\title{
A heterozygous duplication variant of the HOXD13 gene caused synpolydactyly type 1 with variable expressivity in a Chinese family
}

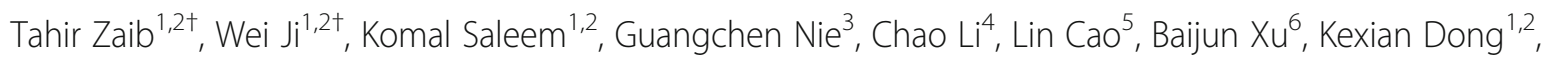
Hanfei $\mathrm{Yu}^{1,2}$, Xuguang $\mathrm{Hao}^{3}$, Yan Xue ${ }^{3}$, Shuhan $\mathrm{Si}^{1,2}$, Xueyuan $\mathrm{Jia}^{1,2}$, Jie Wu ${ }^{1,2}$, Xuelong Zhang ${ }^{1,2}$, Rongwei Guan ${ }^{1,2}$, Guohua $\mathrm{Ji}^{1,2}$, Jing Bai ${ }^{1,2}$, Feng Chen ${ }^{1,2}$, Yong Liu ${ }^{3^{*}}$, Wenjing Sun ${ }^{1,2^{*}}$ and Songbin $\mathrm{Fu}^{1,2^{*}}$ (D)

\begin{abstract}
Background: Synpolydactyly type 1 (SPD1), also known as syndactyly type II, is an autosomal dominant limb deformity generally results in webbing of $3 \mathrm{rd}$ and 4 th fingers, duplication of 4 th or 5 th toes. It is most commonly caused by mutation in HOXD13 gene. In this study, a five-generation Chinese family affected with SPD1 disease were collected. We tried to identify the pathogenic variations associated with SPD1 involved in the family.

Methods: We used the whole genome sequencing (WGS) to identify the pathogenic variant in this family which was later confirmed by PCR-Sanger sequencing. The genetic variation were evaluated with the frequencies in the 1000 Genome Project and Exome Aggregation Consortium (ExAC) dataset. The significance of variants were assessed using different mutation predictor softwares like Mutation Taster, PROVEAN and SIFT. The classification of variants was assessed according to American College of Medical Genetics and Genomics (ACMG) guidelines.
\end{abstract}

Results: Our results showed the mutation of 24-base pair duplication (c.183_

206dupAGCGGCGGCTGCGGCGGCGGCGGC) in exon one of HOXD13 in heterozygous form which was predicted to result in eight extra alanine (A) residues in N-terminal domain of HOXD13 protein. The mutation was detected in all affected members of the family.

Conclusion: Based on our mutation analysis of variant c.183_206dupAGCGGCGGCTGCGGCGGCGGCGGC in HOXD13 and its cosegregation in all affected family members, we found this variant as likely pathogenic to this SPD1 family. Our study highlights variable expressivity of HOXD13 mutation. Our results also widen the spectrum of HOXD13 mutation responsible for SPD1.

Keywords: SPD1, HOXD13, Whole genome sequencing, Variable expressivity

\section{Background}

Synpolydactyly (SPD) is the combination of two inborn limb deformities i.e. syndactyly and polydactyly, and has an autosomal dominant mode of inheritance. It has been

\footnotetext{
*Correspondence: fusb@ems.hrbmu.edu.cn; sunwj@ems.hrbmu.edu.cn; uceduc@163.com

${ }^{t}$ Tahir Zaib and Wei Ji contributed equally to this work.

'Laboratory of Medical Genetics, Harbin Medical University, 157 Baojian Road, Nangang District, Harbin 150081, China

${ }^{3}$ Department of Hand Surgery the Fifth Hospital of Harbin, 27 Jiankang Road, Xiangfang District, Harbin 150040, China

Full list of author information is available at the end of the article
}

classified into three types SPD1, SPD2 and SPD3 [1]. Generally, the clinical features of SPD1 (MIM\#186000) are the webbing of 3rd and 4th fingers, duplication of 4 th or 5 th toes and some other minor deformities $[2,3]$.

Limb development involved highly complex process of growth. Transcriptional regulation and signals of many genes are involved in the process (both at molecular and cellular levels) of limb development. Many genes are known to play important role in early limb development e.g. HOXD13, GLI3, GLI2, SHH, FGF8, WNT7A, etc. Genetic alteration in any of these genes could lead to limb deformities.

(c) The Author(s). 2019 Open Access This article is distributed under the terms of the Creative Commons Attribution 4.0 International License (http://creativecommons.org/licenses/by/4.0/), which permits unrestricted use, distribution, and reproduction in any medium, provided you give appropriate credit to the original author(s) and the source, provide a link to the Creative Commons license, and indicate if changes were made. The Creative Commons Public Domain Dedication waiver (http://creativecommons.org/publicdomain/zero/1.0/) applies to the data made available in this article, unless otherwise stated. 
The mutation in $H O X D 13$ gene located on chromosome $2 \mathrm{q} 31$ is responsible for the SPD1 disease. The HOXD13 gene has two exons that translates into a protein having 335 amino acids and has already been reported several times for SPD1. Different type of mutations at different positions in HOXD13 leads to SPD1 with severe or less severe phenotypes which includes: i) expansion of polyalanine tract in N-terminal region of HOXD13 [2, 4-6], ii) contraction of the polyalanine tract in $\mathrm{N}$-terminal region of HOXD13 [7], iii) nonsense mutations [8], and iv) missense mutations $[9,10]$. Numerous inherited diseases caused due to trinucleotide repeat expansion in specific genes has been reported several times [11-13]. SPD1 is also due to polyalanine expansion in HOXD13 gene [12].

Here, we report a five-generation Chinese family diagnosed with SPD1. The main objective of this study was to identify the genetic factors causing SPD1 in this family. Since multiple genes reported were related with limb deformities, whole-genome sequencing (WGS) was performed on one of the affected members of the family who showed the typical SPD1 phenotype.

\section{Methods}

\section{Subjects}

In this study, a five-generation pedigree of family with 33 individuals from northern China was studied (Fig. 1). There were nine affected members in the family. We comprehensively examined seven affected members (II3, III-1, III-3, III-7, IV-2, IV-11, V-1) of the family with limb deformities. The clinical details and blood samples of the two affected persons IV-7 and IV-8 were not available for study. Photographs and radiographs were obtained after detailed clinical examination. Clinical information and peripheral blood were obtained from 12 persons of the family: $\mathrm{V}-1$ (proband), V-2, IV-2, IV-3, IV-11, III-1, III-3, III-5, III-7, II-3, II-4, and II-5. The peripheral blood was collected into a qualified negative pressure vacuum EDTA anticoagulant tube. The study protocol (HMUIRB20180016) was approved by Institutional Research Board of Harbin Medical University and all participants provided signed informed consent.

\section{Pathogenic gene detection}

There are many genes (SHH, GLI3, LMBR1/ZRS, GJA1, LRP4, BHLHA9, APC, etc.) which have important role in limb development. Genetic alteration in any of these genes could lead to limb deformities. To know about the specific gene mutation that caused SPD1 in the five generation Chinese family, WGS of the blood sample from the typical SPD1 patient IV-2 (affected with both hands and both feet) was performed by Novogene technology limited-liability Company (Beijing, China).

For library generation, $1 \mu \mathrm{g}$ qualified genomic DNA per sample was needed, which was randomly fragmented to approximately 350-base pair by Covaris S220 sonicator. Then, DNA fragments were end-repaired and ligated to prepare DNA library. After determining the size distribution and concentration, the DNA library was sequenced

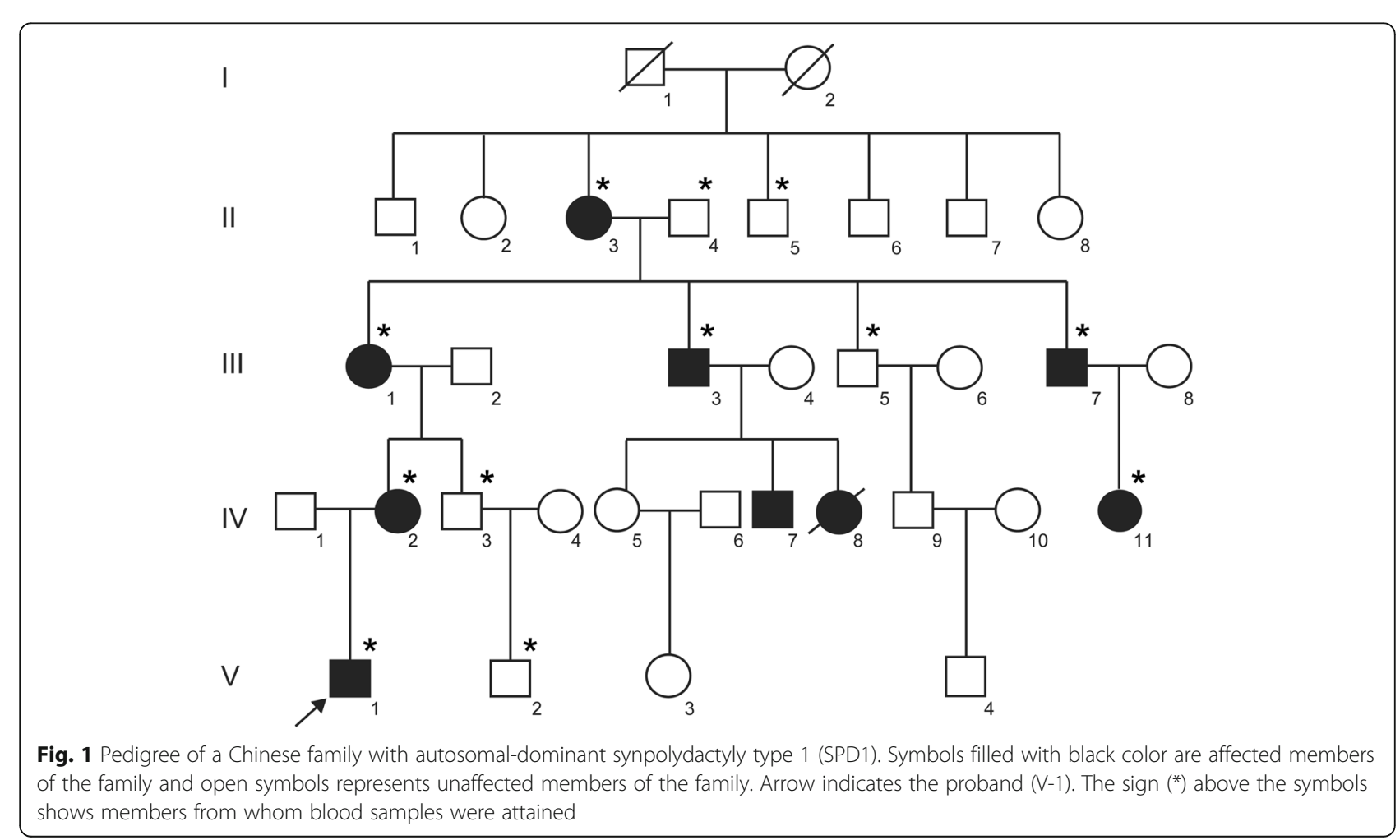


on Illumina Hiseq X platform for paired-end 150-bp reads. The raw image files were processed by Base Calling analysis. The high-quality sequences are compared to the human reference genome (UCSC: GRCH37/hg19) by BurrowsWheeler Aligner (BWA) software [14]. The variation information in the sample is detected, counted and annotated. Samtools mpileup and bcftools were used for variant calling to identify SNP, indels while Control-freec is utilized for $\mathrm{CNV}$ detection. The variant position, variant type, conservative prediction and other information are obtained at this step through a variety of databases, such as dbSNP, 1000 Genome, the Exome Aggregation Consortium (ExAC) and Human Gene Mutation Database (HGMD). Since we focused in exonic variants, gene transcript annotation databases, as Consensus CDS, RefSeq, Ensembl and UCSC were also applied for annotation to determine amino acid alternation. Using these annotation disease related harmful variations were screened. Finally, literature related to SPD1 was reviewed to identify the potential causative variant.

DNA extraction was performed using the DNeasy Blood \& Tissue Kit (Qiagen, \#69506, Dusseldorf, Germany) according to the manufacturer's protocol. Set of primers were designed for exon 1 of HOXD13 (forward primer GGGAATGGGAGGTGGACCCT, and reverse primer CGTGCGGCGATGACTTGA) using the Primer Premier 5 , Software and polymerase chain reaction (PCR) was performed. PCR was performed in a total volume of $20 \mu \mathrm{l}$ $(10 \mu \mathrm{l} 2 \times \mathrm{GC}$ buffer, $2 \mu \mathrm{l} 10 \times \mathrm{dNTPs}, 0.8 \mu \mathrm{l}(10 \mathrm{pmol} / \mu \mathrm{l})$ forward primer, $0.8 \mu \mathrm{l}(10 \mathrm{pmol} / \mu \mathrm{l})$ reverse primer, $0.2 \mu \mathrm{l}$ taq DNA polymerase, $4 \mu \mathrm{l}(5 \mathrm{~mol} / \mathrm{l})$ Betaine, $2 \mu \mathrm{l}$ DNA and $0.2 \mu$ water). The PCR reaction started with an initial 5 min denaturation step at $94^{\circ} \mathrm{C}$, followed by 30 cycles of $25 \mathrm{~s}$ denaturation $\left(94^{\circ} \mathrm{C}\right), 25 \mathrm{~s}$ annealing $\left(60^{\circ} \mathrm{C}\right)$, and $60 \mathrm{~s}$ extension $\left(72^{\circ} \mathrm{C}\right)$, ending with a final extension step of 5 $\min$ at $72^{\circ} \mathrm{C}$. The PCR was carried out on eppendorf Mastercycler nexus GSX1 PCR system. Amplified PCR products were sequenced by TsingKe Biological Technology (Beijing, China) using Sanger sequencing. Results of Sanger sequencing were analyzed using different softwares (Chromas, Megalign and Editseq).

Then the PCR products were purified using QIAquick Gel Extraction Kit following the manufacturer's protocol. The purified PCR products were ligated to the T linear vector (pEasy-T1 Simple Cloning Kit, \#CT111, Transgen, Beijing, China) according to the manufacturer's protocol and sequenced by TsingKe Biological Technology using Sanger sequencing.

\section{Bioinformatic analysis of variants}

The frequency of variants were evaluated in the 1000 Genome Project (www.1000genomes.org) and ExAC (exac.broadinstitute.org). Suspected variants with frequency $<0.01$ were considered for analysis.
The significance of variants were assessed to evaluate their impact on protein structure, protein function and evolutionary conservation using different mutation predictor softwares like Mutation Taster (www.mutationtaster.org), PROVEAN (provean.jcvi.org) and SIFT (sift.bii. a-star.edu.sg). Conservation of the mutation locus was patterned through Aminode (www.aminode.org). The effects of the mutation on protein structure were assessed using SWISS-MODEL (www.swissmodel.expasy.org/).

The standard, guidelines and recommendations for the classification of variants given by American College of Medical Genetics and Genomics (ACMG) were also analyzed for the candidate gene variant [15].

\section{Results}

\section{Clinical findings}

The proband (V-1) was a 12-year-old boy who has been diagnosed with SPD1. The family medical history was further investigated for the disease occurrence. The affected family includes 33 persons in five generations (Fig. 1). Generally, nine members of this family have been suffered from autosomal dominant SPD1. The seven affected members of the family from whom blood samples had been obtained were carefully examined for SPD1 (Table 1). Photographs and radiographs were obtained for affected family members of the family (Figs. 2 and 3). Clinical examination of other family members did not show any sign and symptoms of SPD1 or other limb abnormalities.

\section{Mutation analysis revealed 24-base pair duplication variant in exon 1 of HOXD13}

To identify the disease gene behind SPD1, we performed WGS of patient (IV-2) as she was the only patient with the typical symptoms of SPD1 in the family affected with both hands and both feet. Pathogenic analysis of WGS data revealed 16 pathogenic, 1 likely pathogenic, 2511 variants of uncertain significance (VUS) and 24,319 benign variants. Further analysis of WGS results revealed total of 10,883 missense mutations, 57 frameshift insertions, 183 non-frameshift insertions, and 194 nonframeshift deletions. We have checked all the rare variants falling in syndactyly/limb developmental genes which have been presented in Additional file 1: Table S1. We found their population frequencies were higher than 0.01 . The literature related to SPD1 disease was reviewed, and we found that mutation in HOXD13 gene is the most widely reported for SPD1 disease. Comprehensive analysis of WGS results revealed the duplication of 24-base pair at chr2:176957801-176,957,823 (GRCH37/hg19), which caused a non-frameshift mutation in HOXD13. A heterozygous duplication variant c.183_206dupAGCGGCGGCTGCGGCGGCGGCGGC in exon one of HOXD13 gene was identified in patient (IV-2) by WGS. This mutation is predicted to 
Table 1 Clinical characteristics of all affected family members

\begin{tabular}{|c|c|c|c|c|c|}
\hline Family ID & Gender & $\begin{array}{l}\text { Age } \\
\text { (years old) }\end{array}$ & Deformities in hands & Deformities in feet & Operation \\
\hline$\|-3$ & Female & 71 & $\begin{array}{l}\text { Syndactyly the 3rd and } \\
\text { 4th fingers of both hands }\end{array}$ & None & \\
\hline|| $\mid-1$ & Female & 53 & $\begin{array}{l}\text { Syndactyly the 3rd and } \\
\text { 4th fingers of both hands }\end{array}$ & Little toe polydactyly of right foot & $\begin{array}{l}\text { Corrective surgery for both hands, } \\
\text { removal of the } 6 \text { th toes of right foot }\end{array}$ \\
\hline$|1|-3$ & Male & 52 & None & Little toe polydactyly of right foot & \\
\hline$|1|-7$ & Male & 45 & $\begin{array}{l}\text { Syndactyly the 3rd and } \\
\text { 4th fingers of left hand }\end{array}$ & Little toe polydactyly of right foot & \\
\hline IV-2 & Female & 31 & $\begin{array}{l}\text { Syndactyly the } 3 \mathrm{rd} \text { and } \\
\text { 4th fingers of both hands }\end{array}$ & Little toe polydactyly of both feet & Removal of the 6th toe of both feet \\
\hline IV-11 & Female & 22 & $\begin{array}{l}\text { Camptodactyly of the right } \\
\text { 5th finger and clinodactyly } \\
\text { of the left 5th finger }\end{array}$ & $\begin{array}{l}\text { Camptodactyly of toes and contracture } \\
\text { in right hallux }\end{array}$ & \\
\hline V-1 & Male & 12 & $\begin{array}{l}\text { Syndactyly the 3rd and } \\
\text { 4th fingers of right hand }\end{array}$ & Little toe polydactyly of both feet & Removal of the 6th toe of both feet \\
\hline
\end{tabular}

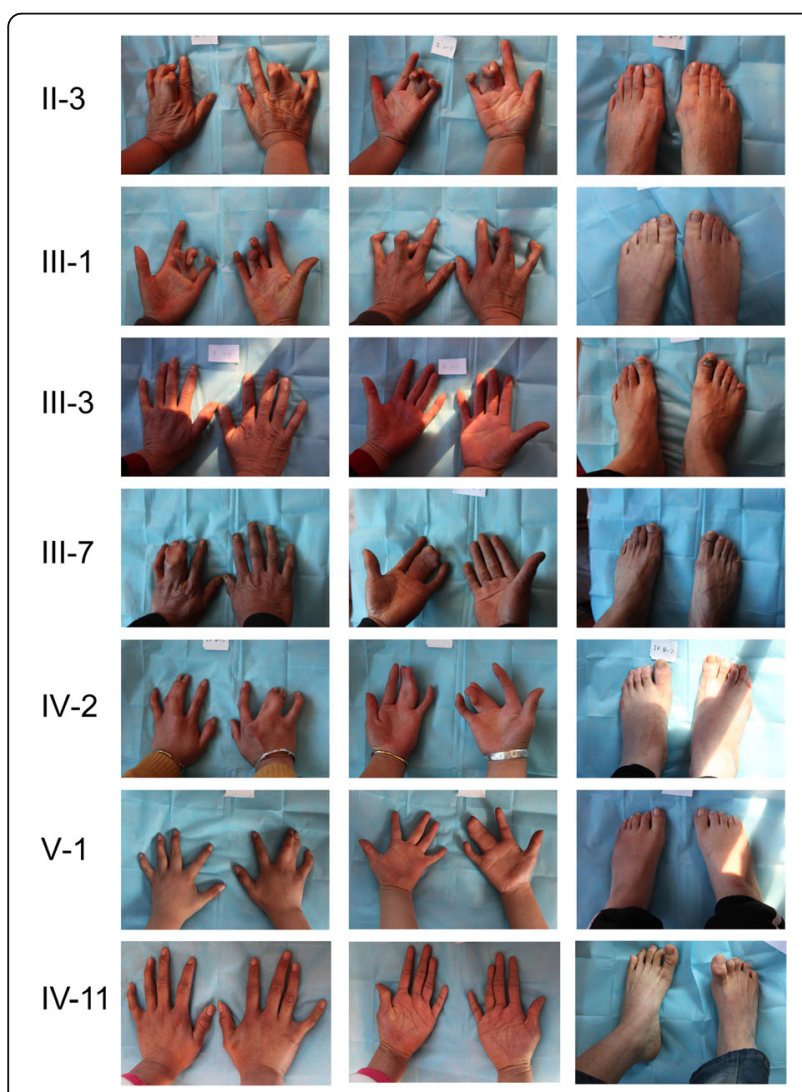

Fig. 2 Photographs of the affected members of the family showing hand and foot deformities results in addition of eight extra alanine (A) residues in N-terminal domain of HOXD13 protein. The WGS data can be accessed at SRA accession: PRJNA504318 (www.ncbi.nlm.nih.gov/ sra/PRJNA504318).

To determine whether the mutation in HOXD13 gene was co-segregated in other family members or not, targeted DNA fragments from the patient (IV-2) and other 11 individuals including six patients (II-3, III-1, III-3, III-7, IV-11, V-1) and five normal persons (II-4, II-5, III-5, IV-3, V-2) were first amplified by PCR and then sequenced by Sanger sequencing. The Sanger sequencing results showed that five normal persons did not carry the duplication variant (Fig. 4A. $\mathrm{V}-2$ ) and all the affected persons carried the 24-base pair duplication variant (Fig. 4B. V-1 \& 4C. IV-11).

Further investigation was performed into the two affected persons (V-1 and IV-2) sequence by ligating the purified PCR products with the $\mathrm{T}$ linear vector, then followed by subcloning and Sanger sequencing. The sequencing results showed that both patients ( V1 and IV-2) carried one normal sequence (Fig. 5A. V1) and one mutated sequence (Fig. 5B. V-1) which indicated that mutation exists in heterozygous form. The normal sequence and the mutation sequence can be accessed at GenBank: MK290763 for normal one, and MK290762 for the HOXD13 c.183 206dupAGCGGCGGCTGCGGCGGCGGCGGC.

\section{Bioinformatic analysis of the identified 24-base pair duplication variant of HOXD13 Frequency}

The 24-base pair duplication variant in exon one of HOXD13 was neither found in 1000 Genome project nor in ExAC and has been absent in these population data bases. 


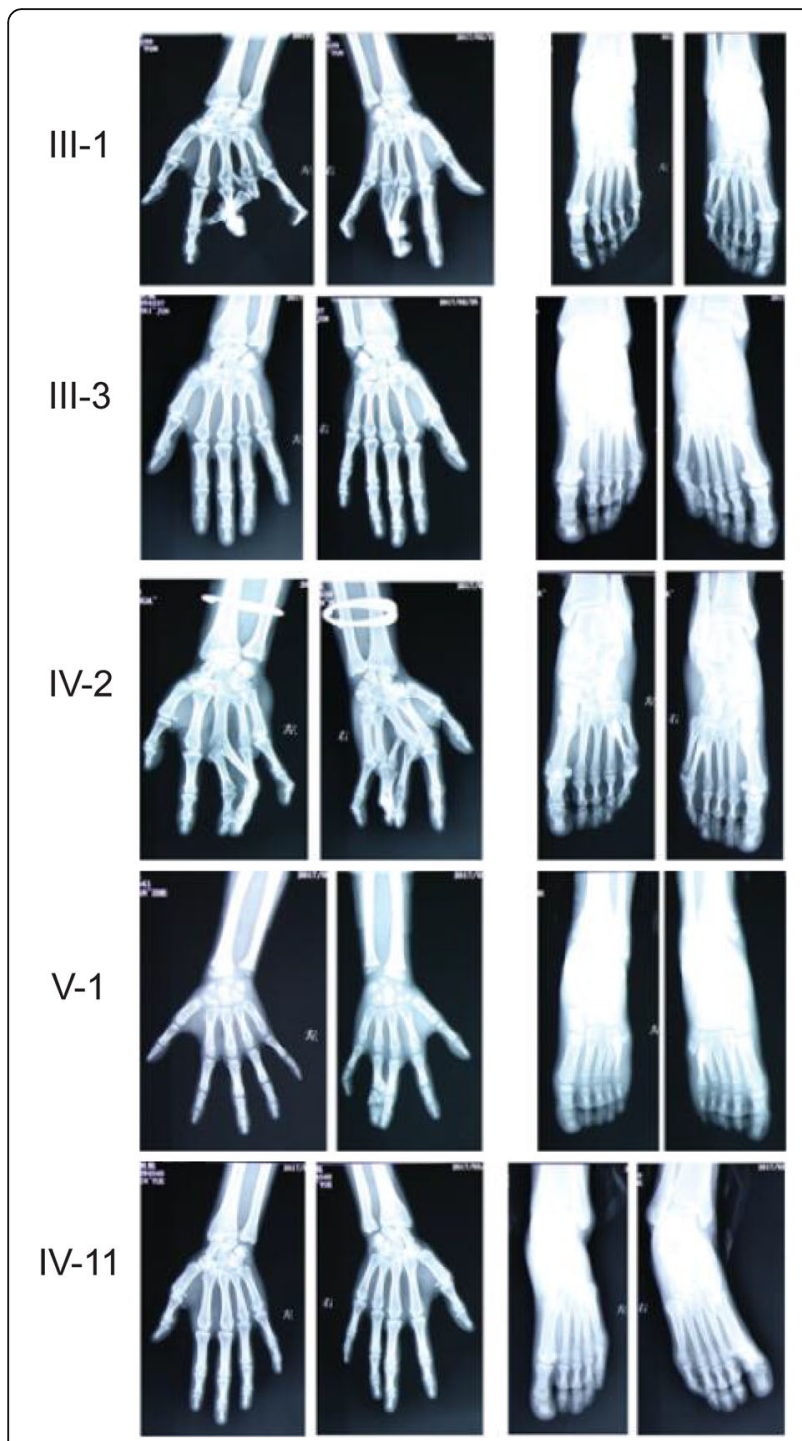

Fig. 3 Radiographs of the affected members of the family in which hand and foot deformities are clearly visible

\section{In silico predictions}

Mutation taster predicted polymorphism for it, while PROVEAN predicted it as deleterious with the score of - 2.719. SIFT predicted the variant as neutral.

\section{Evolutionarily constrained region of HOXD13}

Evolutionarily constrained regions (ECRs) of HOXD13 according to Aminode revealed that the polyalanine tract (p.57-71) of the HOXD13 protein was conserved among different species, such as Mus musculus and Rattus norvegicus, etc. (Fig. 6A).

\section{Homology model for the HOXD13 protein}

A homology model of wildtype and mutant HOXD13 proteins revealed that the 24-base pair duplication variant encoding eight extra alanine (A) residues in the polyalanine tract locally affected the shape and results in increase in size of the protein (Fig. 6B).

\section{ACMG evaluation for 24-base pair duplication variant of HOXD13}

According to classification of ACMG for assessing the pathogenicity of different variants, the 24-base pair duplication variant of HOXD13 is "likely pathogenic" as it is in mutation hot spot (PM1), absent in population data bases (PM2), co-segregated in affected members of the family (PP1), computational evidence showed deleterious effect (PP3), and highly specific disease phenotype (SPD1) with single gene (HOXD13) (PP4). Thus, according to ACMG the 24-base pair duplication mutation of HOXD13 has two moderate (PM1, PM2) and more than two supportive (PP1, PP3, PP4) evidences of pathogenicity, fulfilled the criteria of ACMG for "likely pathogenic" variant.

\section{Discussion}

Synpolydactyly is a limb deformity in which hands and feet of the patient get affected and inherited in an autosomal dominant pattern from one generation to the next. Mutation in HOXD13 gene located in chromosome 2q31 is responsible for the SPD1 disease. In this study, we found a heterozygous duplication variant (c.183 206dupAGCGGCGGCTGCGGCGGCGGCGGC) in exon 1 of HOXD13 [NM_000523.3] in a five-generation Chinese family with SPD1.

Complete cosegregation of the variant with the disease was evident in this family, which is the most reliable way to evaluate the pathogenicity of a variant. In our case, duplication of 24-base pair in exon 1 of HOXD13 were found in all affected members (II-3, III-1, III-3, III-7, IV$2, \mathrm{IV}-11$ and $\mathrm{V}-1$ ) of the family. It encodes additional eight alanine (A) residues in the polyalanine tract at $\mathrm{N}$ terminal domain of HOXD13 protein. There are 15 alanine residues present in $\mathrm{N}$-terminal domain of wildtype HOXD13 protein, due to 24-base pair duplication mutation consequently the number of alanine residues increases to 23 (15 aa plus 8 aa).

Some previous studies also reported addition of 7-14 extra polyalanine tract expansions in families with SPD $[2,4-6,16-22]$, but our results are different from the previously reported families in terms of variable expressivity. Goodman et al. reported the families from British and German populations with SPD having duplication of 24-base pair in exon one of HOXD13 and eight extra polyalanine expansions [5], while Xin et al. reported a family with SPD in Chinese population having eight extra polyalanine expansions in HOXD13 [2]. But the exact site of the duplication was not mentioned in both studies. Chinese family reported by Xin et al. showed SPD features that were consistent with our SPD family as most of the SPD patients had fusion of fingers 3rd 

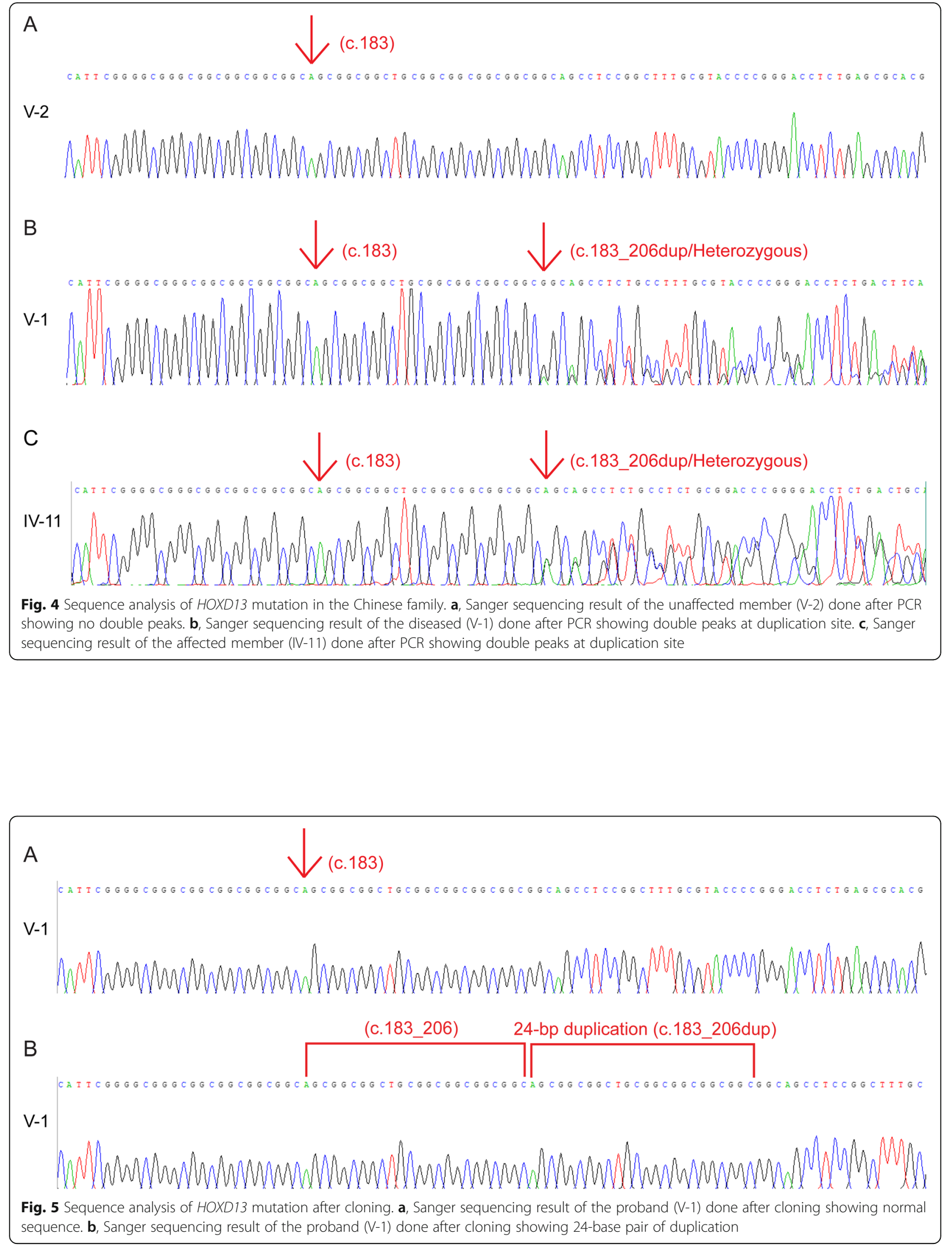


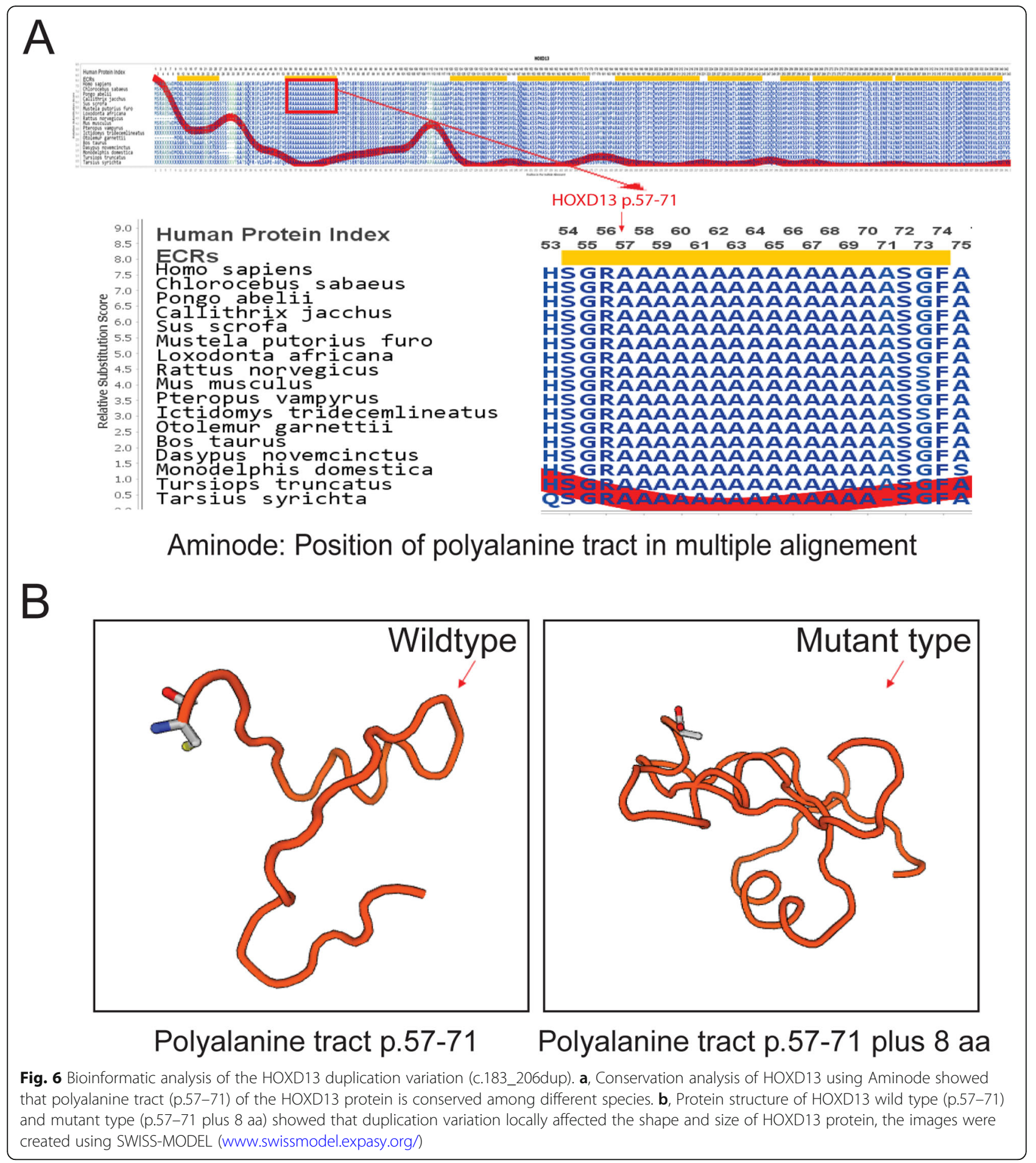

and 4th and little toe polydactyly of right or left foot, but our patients have more severe features of SPD. In our SPD family, three out of seven SPD patients have both hands affected with syndactyly, while in case of family reported by Xin et al. only two out of seven SPD patients had syndactyly in both hands. Furthermore, according to Xin et al. older generations were more severely affected than younger generations, while in our SPD family older and younger generations were equally affected i.e. family members II-3, III-1, III-7, IV-2 and $\mathrm{V}-1$ showed severe complications of SPD1.

Several other different types of mutations had also been reported for SPD1 in HOXD13, i.e. deletions [7, 23], nonsense mutations $[8,24,25]$ and missense mutations $[9,10,26-32]$, 
but most common amongst all was expansion of polyalanine repeats [2]. Therefore, polyalanine repeats in N-terminal region of HOXD13 is a mutational hot spot and mutation in this region will comes under category PM1 (moderate evidence of pathogenicity) according to classification of ACMG for classifying pathogenic variants [15].

HOXD13 encodes highly conserved DNA binding transcription factors that helps other genes to initiate their transcription. Hyperexpansion of DNA-triplet repeats as a result of 24-base pair duplication in exon 1 of HOXD13 may lead to altered transcription or translational activities which can result in defective mRNA and ultimately defective proteins. Polyalanine expansions in other transcription factors had been reported to be linked with human birth defects such as deformities of digits and other structures [6].

In vertebrates $H O X$ genes have significant role of morphogenesis which translates into a group of some greatly conserved transcription factors [33]. Deep investigation of five HOX genes (HOXD9-HOXD13) in mouse and chick revealed that it has extremely vital role in development of limbs [34]. These genes seem to play the same role in humans as mutations in HOXD13 gene were previously reported to be responsible for SPD1 cases [2, 4, 5, 7].

In case of variable expressivity or gene expression, some family members show severe complications of synpolydactyly (II-3, III-1, III-7, IV-2, V-1) while other did not show the same complications (III-3, IV-11) (Fig. 2). The five generation Chinese family showed from minor to more severe limb deformities, which are beneficial for further understanding of SPD1 clinical features in future. Camptodactyly and clinodactyly of 5th finger and toes and contracture in right foot's hallux have been added to the list of possible phenotypes caused by HOXD13 polyalanine expansion mutations.

The variable phenotypes of SPD1 patients in this family predicts that some other factors (environmental or genetic) can contribute to the expression of HOXD13, as some genetic factors (e.g. gene modifiers) and epigenetic factors also found to play an important role in controlling the expression of any specific gene. Phenotypic heterogeneity of any disorder is because of interaction of responsive gene with other associated genetic factors or modifier genes. Raj et al. also showed that mutation in that locus or gene which is critical for developmental process could lead to variable expressivity [35]. Though, number of mutations in HOXD13 has been reported up till now to be linked with SPD1 disease, but still a clear genotype-phenotype association is not well established. Detail investigation of 32 SPD1 families by Malik et al. also revealed a weak genotype-phenotype correlation [1].

\section{Conclusions}

We successfully identified duplication mutation (c.183 206dupAGCGGCGGCTGCGGCGGCGGCGGC) in exon
1 of HOXD13 [NM_000523.3]. Based on clinical data, cosegregation analysis, in silico predictions and ACMG assessment, we classified the HOXD13 24-base pair duplication variant as likely pathogenic and the main cause of SPD1 in this family. Our results widen the genotypic spectrum of HOXD13 mutations that are responsible for SPD1. The phenomena of variable expressivity were quite obvious in this family. In comparison with previous studies it is established that the variable expressivity is the common phenomena in SPD1. More research is required in the area to find out the genetic factors behind phenotypic heterogeneity.

\section{Supplementary information}

Supplementary information accompanies this paper at https://doi.org/10. 1186/s12881-019-0908-6.

Additional file 1: Table S1. Mutations in limb development genes found in WGS

\section{Abbreviations}

ACMG: American College of Medical Genetics and Genomics; BWA: BurrowsWheeler Aligner; ECRs: Evolutionarily constrained regions; ExAC: Exome Aggregation Consortium; HGMD: Human Gene Mutation Database; PCR: polymerase chain reaction; SPD1: Synpolydactyly type 1; VUS: Variants of uncertain significance; WGS: Whole Genome Sequencing

\section{Acknowledgements}

We thank all family members for their participation.

\section{Authors' contributions}

TZ, WJ, KS, SF, WS and YL were involved in all aspects of this study. TZ, WJ and KS conducted experiments. TZ and XJ performed WGS data analyses. TZ, WJ, KD, HY, SS, JW, XZ, RG, GJ, JB and FC conducted bioinformatics study and analyses. $Y L, G N, C L, L C, X H, Y X$ and $B X$ involved in patients care. $T Z$ and WJ did literature review and drafted this manuscript. SF, WS, WJ and KS critically reviewed this manuscript. All authors participated in manuscript formation by providing comments and suggestions. All authors read and approved the final manuscript.

\section{Funding}

This work is supported by the National Key Research and Development Program (No. 2016YFC1000504, to SF). The funding body contributed to the design of study and collection, analysis, and interpretation of data.

\section{Availability of data and materials}

The WGS data can be accessed at SRA accession: PRJNA504318 (www.ncbi. nlm.nih.gov/ sra/PRJNA504318).

\section{Ethics approval and consent to participate}

The study was approved by Institutional Research Board of Harbin Medical University (Harbin, China). The protocol number was HMUIRB20180016. Written, informed consent was obtained for all involved patients, consent for individual under 16 years-old was given by his parent.

\section{Consent for publication}

All the participants provided the signed informed consent, while consent for individual under 18 years-old was given by his parent. The study was approved by Institutional Research Board of Harbin Medical University.

\section{Competing interests}

The authors declare that they have no competing interests.

\section{Author details}

${ }^{1}$ Laboratory of Medical Genetics, Harbin Medical University, 157 Baojian Road Nangang District, Harbin 150081, China. ${ }^{2}$ Key Laboratory of Preservation of 
Human Genetic Resources and Disease Control in China (Harbin Medical University), Ministry of Education, Harbin, China. ${ }^{3}$ Department of Hand Surgery the Fifth Hospital of Harbin, 27 Jiankang Road, Xiangfang District, Harbin 150040, China. ${ }^{4}$ Department of Orthopaedic Surgery the Second Affiliated Hospital of Harbin Medical University, Harbin 150086, China. ${ }^{5}$ Department of Hepatopancreatobiliary Surgery the Second Affiliated Hospital of Harbin Medical University, Harbin 150086, China. ${ }^{6}$ Department of Radiology Suihua Cancer Hospital, Suihua 152000, China.

Received: 17 January 2019 Accepted: 15 October 2019

Published online: 23 December 2019

\section{References}

1. Malik S, Grzeschik KH. Synpolydactyly: clinical and molecular advances. Clin Genet. 2008:73(2):113-20

2. Muragaki Y, Mundlos S, Upton J, Olsen BR. Altered growth and branching patterns in synpolydactyly caused by mutations in HOXD13. Science. 1996; 272(5261):548-51.

3. Goodman FR. Limb malformations and the human HOX genes. Am J Med Genet. 2002;112(3):256-65

4. Akarsu AN, Stoilov I, Yilmaz E, Sayli BS, Sarfarazi M. Genomic structure of HOXD13 gene: a nine polyalanine duplication causes synpolydactyly in two unrelated families. Hum Mol Genet. 1996;5(7):945-52.

5. Goodman FR, Mundlos S, Muragaki Y, Donnai D, Giovannucci-Uzielli ML, Lapi E, Majewski F, McGaughran J, McKeown C, Reardon W, et al. Synpolydactyly phenotypes correlate with size of expansions in HOXD13 polyalanine tract. Proc Natl Acad Sci U S A. 1997;94(14):7458-63.

6. Gong L, Wang B, Wang J, Yu H, Ma X, Yang J. Polyalanine repeat expansion mutation of the HOXD13 gene in a Chinese family with unusual clinical manifestations of synpolydactyly. Eur J Med Genet. 2011;54(2):108-11.

7. Goodman F, Giovannucci-Uzielli ML, Hall C, Reardon W, Winter R, Scambler P. Deletions in HOXD13 segregate with an identical, novel foot malformation in two unrelated families. Am J Hum Genet. 1998:63(4):992-1000.

8. Kurban M, Wajid M, Petukhova L, Shimomura Y, Christiano AM. A nonsense mutation in the HOXD13 gene underlies synpolydactyly with incomplete penetrance. J Hum Genet. 2011;56(10):701-6.

9. Fantini S, Vaccari G, Brison N, Debeer P, Tylzanowski P, Zappavigna V. A G220V substitution within the N-terminal transcription regulating domain of HOXD13 causes a variant synpolydactyly phenotype. Hum Mol Genet. 2009; 18(5):847-60.

10. Caronia G, Goodman FR, McKeown CM, Scambler PJ, Zappavigna V. An 147L substitution in the HOXD13 homeodomain causes a novel human limb malformation by producing a selective loss of function. Development. 2003; 130(8):1701-12.

11. Ranum LP, Day JW. Dominantly inherited, non-coding microsatellite expansion disorders. Curr Opin Genet Dev. 2002;12(3):266-71.

12. Albrecht $A$, Mundlos $S$. The other trinucleotide repeat: polyalanine expansion disorders. Curr Opin Genet Dev. 2005:15(3):285-93.

13. Cummings $\mathrm{CJ}$, Zoghbi HY. Fourteen and counting: unraveling trinucleotide repeat diseases. Hum Mol Genet. 2000;9(6):909-16.

14. Li H, Durbin R. Fast and accurate short read alignment with burrowswheeler transform. Bioinformatics. 2009;25(14):1754-60.

15. Richards S, Aziz N, Bale S, Bick D, Das S, Gastier-Foster J, Grody WW, Hegde

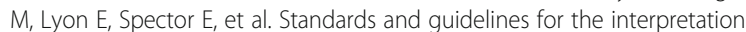
of sequence variants: a joint consensus recommendation of the American College of Medical Genetics and Genomics and the Association for Molecular Pathology. Genet Med. 2015;17(5):405-24.

16. Kjaer KW, Hansen L, Eiberg H, Utkus A, Skovgaard LT, Leicht P, Opitz JM, Tommerup N. A 72-year-old Danish puzzle resolved--comparative analysis of phenotypes in families with different-sized HOXD13 polyalanine expansions. Am J Med Genet A. 2005;138(4):328-39.

17. Horsnell K, Ali M, Malik S, Wilson L, Hall C, Debeer P, Crow Y. Clinical phenotype associated with homozygosity for a HOXD13 7-residue polyalanine tract expansion. Eur J Med Genet. 2006:49(5):396-401.

18. Wajid M, Ishii Y, Kurban M, Dua-Awereh MB, Shimomura Y, Christiano AM. Polyalanine repeat expansion mutations in the HOXD13 gene in Pakistani families with synpolydactyly. Clin Genet. 2009;76(3):300-2.

19. Jin H, Lin PF, Wang QM, Mao F, Cai Y, Gong YQ. Synpolydactyly in a Chinese kindred: mutation detection, prenatal ultrasonographic and molecular diagnosis. Zhonghua Yi Xue Yi Chuan Xue Za Zhi. 2011; 28(6):601-5.
20. Xin Q, Li L, Li J, Qiu R, Guo C, Gong Y, Liu Q. Eight-alanine duplication in homeobox D13 in a Chinese family with synpolydactyly. Gene. 2012;499(1):48-51.

21. Warren ST. Polyalanine expansion in synpolydactyly might result from unequal crossing-over of HOXD13. Science. 1997;275(5298):408-9.

22. Li Y, Xin Q, Shan S, Li J, Liu Q. mutation analysis of HOXD13 gene in a Chinese family affected with autosomal dominant synpolydactyly. Zhonghua Yi Xue Yi Chuan Xue Za Zhi. 2015;32(4):481-4.

23. Radhakrishnan P, Nayak SS, Pai MV, Shukla A, Girisha KM. Occurrence of Synpolydactyly and Omphalocele in a fetus with a HOXD13 mutation. Journal of pediatric genetics. 2017;6(3):194-7.

24. Low KJ, Newbury-Ecob RA. Homozygous nonsense mutation in HOXD13 underlies synpolydactyly with a cleft. Clin Dysmorphol. 2012;21(3):141-3.

25. Wang B, Li N, Geng J, Wang Z, Fu Q, Wang J, Xu Y. Exome sequencing identifies a novel nonsense mutation of HOXD13 in a Chinese family with synpolydactyly. Congenit Anom (Kyoto). 2017;57(1):4-7.

26. Debeer P, Bacchelli C, Scambler PJ, De Smet L, Fryns JP, Goodman FR. Severe digital abnormalities in a patient heterozygous for both a novel missense mutation in HOXD13 and a polyalanine tract expansion in HOXA13. J Med Genet. 2002;39(11):852-6.

27. Nakano K, Sakai N, Yamazaki Y, Watanabe H, Yamada N, Sezaki K, Susami T, Tokunaga K, Takato T, Uchinuma E. Novel mutations of the HOXD13 gene in hand and foot malformations. Int Surg. 2007:92(5):287-95.

28. Brison N, Debeer P, Fantini S, Oley C, Zappavigna V, Luyten FP, Tylzanowski P. An N-terminal G11A mutation in HOXD13 causes synpolydactyly and interferes with Gli3R function during limb pre-patterning. Hum Mol Genet. 2012;21(11):2464-75

29. Wang B, Xu B, Cheng Z, Zhou X, Wang J, Yang G, Cheng L, Yang J, Ma X. A novel non-synonymous mutation in the homeodomain of HOXD13 causes synpolydactyly in a Chinese family. Clin Chim Acta. 2012;413(13-14):1049-52.

30. Zhou X, Zheng C, He B, Zhu Z, Li P, He X, Zhu S, Yang C, Lao Z, Zhu Q, et al. A novel mutation outside homeodomain of HOXD13 causes synpolydactyly in a Chinese family. Bone. 2013;57(1):237-41.

31. Dai L, Liu D, Song M, Xu X, Xiong G, Yang K, Zhang K, Meng H, Guo H, Bai Y. Mutations in the homeodomain of HOXD13 cause syndactyly type 1-c in two Chinese families. PLoS One. 2014;9(5):e96192.

32. Zhao XL, Meng JP, Sun M, Ao Y, Wu AH, Lo HY, Zhang X. HOXD13 polyalanine tract expansion in synpolydactyly: mutation detection and prenatal diagnosis in a large Chinese family. Zhonghua Yi Xue Yi Chuan Xue Za Zhi. 2005;22(1):5-9.

33. Krumlauf R. Hox genes in vertebrate development. Cell. 1994;78(2):191-201.

34. Zakany J, Duboule D. Synpolydactyly in mice with a targeted deficiency in the HoxD complex. Nature. 1996;384(6604):69-71.

35. Raj A, Rifkin $S A$, Andersen $E$, van Oudenaarden A. Variability in gene expression underlies incomplete penetrance. Nature. 2010;463(7283):913-8.

\section{Publisher's Note}

Springer Nature remains neutral with regard to jurisdictional claims in published maps and institutional affiliations.

Ready to submit your research? Choose BMC and benefit from

- fast, convenient online submission

- thorough peer review by experienced researchers in your field

- rapid publication on acceptance

- support for research data, including large and complex data types

- gold Open Access which fosters wider collaboration and increased citations

- maximum visibility for your research: over $100 \mathrm{M}$ website views per year

At BMC, research is always in progress.

Learn more biomedcentral.com/submission 